\section{ADMINISTRATION OF SANATORIUM} BENEFIT IN TOWNS.*

BY PHILIP BOOBBYER, M.D., Medical Officer of Health, Nottingham.

THE whole ideal scheme of the Government for the administration of sanatorium henefit has been so fully set out in the Astor Report and subsequent memoranda of the Local Government Board, that it seems hardly necessary to repeat its description as a preamble to the discussion of its details. Still, as it is obviously better to say too much than too little in dealing with a matter of such importance as this, I shall risk the reproach of redundancy by considering very briefly the whole armamentarium of prevention and treatment while offering suggestions for its application to the special needs of towns and cities.

The heart of the scheme is the dispensary, which is at once a head office, a clearing house, a diagnosis and treatment centre, an information and an instruction bureau for the entire movement.

The area and population to be served by each dispensary in town districts has been variously stated, but the Local Government Board memorandum of May I4th, I9I2, suggested 150,000 to 200,000 as the population figure for each town dispensary in the immediate future. While centralization in the administrative department necessarily makes alike for economy and efficiency, the fact must not be lost sight of, that, even with the best modern means of communication, it is undesirable in a large proportion of cases to call upon the patients to travel long distances. In a town like Nottingham, with a population of 265,000 , and a long diameter of more than seven miles, we have started with one central dispensary, but in all probability branch establishments will ultimately be called for. $t$ The experience of schools for mothers and school clinics in this connection all points to such a conclusion.

As regards accommodation and equipment, the appended description of what has been found necessary at our own central dispensary will serve as an example of minimum requirements.

This dispensary is for the service of the city only. At the outset, in deference to the

${ }^{*}$ Read before a Meeting of the Society of Medical Officers of Health, on 11 h April, 1913 .

I Inay mention here the projected incorporation of the Mothers' and Babies Welcomes in the dispensary scheme. It is now proposed to use these Welcomes as branch dispensaries, especially for the ex mination, sorting, and treatment of childen suftering, or reputed of the se institutions. suggestion of various authoritative reports and memoranda on the subject, the question of union with the county or other outside body or bodies was considered, but the ultimate decision, on the part of practically all persons consulted, and in the interests of all parties concerned, was unfavourable to such amalgamation. It was felt that administrative difficulties would constitute an almost insuperable bar to the possibility of such union.

The Central Dispensary building consists of a house of 13 rooms, utilized as follows :One room as an office, one as a committee room, one as a waiting-room, two as consultingrooms, two as dressing-rooms (one each for either sex), one as (drug) dispensary, one as a laboratory and laryngoscopic room. The four remaining rooms may serve for the residential accommodation of one or two nurses and one servant.

The fitting and furnishing of such a house for the purpose of a dispensary, as above described, can, with very strict economy, be carried out in sufficient completeness at any rate to render it reasonably efficient, at a cost of $£ 500$, and, according to the Departmental Committee's Report (pages 26 and 27), $£_{400}$, or four-fifths of this, should be obtainable from the Treasury, leaving $\&$ Ioo only to be provided from the local rates. So much for capital outlay.

The staff consists, or is to consist, of the tuberculosis officer, one assistant, to serve as clerk, dispenser, and occasional bacteriologist, one dispensary nurse and two visiting nurses. It should be noted that the major part of the bacteriological work required will be done by the City Bacteriologist and Pathologist, who has a well-equipped laboratory provided by and connected with the Health Department. This is a brief description in outline of the dispensary as an isolated unit.

Inasmuch; however, as the clinical section of the curative and preventive work must necessarily go hand in hand with public health and housing reform, if the new department is to fulfil itself satisfactorily, it is, to say the least, highly desirable that the dispensary administration should be closely linked up with the Health and Housing Departments. This union, or co-ordination, should be a matter of definite arrangement from the outset, and there is obviously one official in whose person and office the union should be centred, and that is the medical officer of health.

The tuberculosis dispensary and the sanatorium, to be presently described, are provided 
by the Health Department, and, in our city, in order to emphasize the necessity for union between the several municipal agencies operating to improve the public health, and to afford the greatest possible facility for co-operation between the Health and Housing Departments and the new Tuberculosis Department, the tuberculosis officer has been appointed also the deputy medical officer of health. As the headship of all sections of the Health and Housing Departments is vested in the medical officer of health, this arrangement will enable the tuberculosis officer to deal directly with any health or housing matters requiring attention which may come to his cognizance, directly, through the office of the medical officer of health, including, inter alia, such matters as those connected with the supervision of milk and other foods.

A few words now as to the relation of the local Insurance Committee to the scheme. No binding agreement at present exists between the Corporation and the local Insurance Committee, but the latter have practically undertaken to administer sanatorium benefit exclusively by the agency of the local authority, and in pursuance of this undertaking the scheme set out in this paper has been organized.

The tuberculosis officer, appointed and paid by the Corporation and acting as expert adviser to the Insurance Committee, serves as the official personal link between these two bodies.

Owing to the official approval of such an arrangement as here described betwoen the local Insurance Committee and the Local Authority already given by the Local Government Board, and the obvious advantage of it so far at least as the majority of our towns and cities are concerned, I shall here presume it to be the generally accepted order, and make no reference to possible alternative arrangements of a less convenient character.

No patients from outside the City of Nottingham have hitherto been admitted to the City Sanatorium, nor is the admission of such patients at present in contemplation. All available space in the sanatorium is likely to be required in the near future for Nottingham patients. I may mention, however, that several outside authorities have applied for beds.

I shall next proceed to discuss very shortly the routine practice and work of the tuberculosis officer and his staff, but must premise that certain details of work here described, though definitely contemplated, are not yet in actual operation.
Every case of tuberculosis, or reputed tuberculosis, brought to the notice of the department is visited by one of the outside nurses or inspectors, who takes notes of the following matters:-The situation, the size, the rental, and the sanitary condition of the house in which the patient is domiciled, the number of inmates, their ages and sex and relations to one another, their state of health, present and past, and the amount of money per week earned by the members of the family group to which the patient belongs or otherwise reaching the family coffers. The visiting nurses carry with them note-books, in which these particulars respecting the houses and persons are entered, and from which they are transferred to separate sheets (one for each patient and his family unit), daily, at the dispensary. Any sanitary defect or other kindred matter discovered in the course of these visits is reported to the appropriate department:

If the patient has not a medical attendant he is at once examined at his own house, or the dispensary, and a full description of his case entered up in the class to which the latter is held to belong, together with a note of the line of treatment to be adopted for him-e.g., whether his case be medical or surgical in character, whether domiciliary, dispensary, hospital or sanatorium treatment is called for.

With regard to observation beds, it was at first intended to establish these at the dispensary, but, in the interests alike of the patients and the administration, it was ultimately decided to place them at the sanatorium, and this arrangement I have no doubt will be adopted elsewhere whenever the sanatorium is properly equipped and conveniently situated.

Tuberculin treatment, moreover, is now almost exclusively given at the sanatorium, where the patients, of course, are under continual medical supervision. I need not explain the advantage of this arrangement as compared with home treatment of the same description. If a medical man is in charge of the case, a stereotyped letter is sent to him reminding him of the lines of treatment appropriate to different types of cases which are available under the new régime, and offering the services of the dispensary staff in promoting the efficacy of domiciliary treatment.

Shelters, to be used by patients undergoing dispensary and domiciliary treatment, will be provided by the Corporation under an arrangement with the Insurance Committee, but in 
towns there must obviously be less scope for the advantageous use of such shelters than in rural areas.

Systematic disinfection of all houses known to contain phthisical patients is carried out by the Health Department, in all cases where consent can be obtained, as far as possible at regular and frequent intervals.

I may here perhaps be allowed to indulge in a brief parenthesis on domiciliary treatment. Owing to the importance this treatment is almost certain to assume under the existing arrangements by which a pool of sixpence per head of insured persons is provided for the payment of general practitioners on the local panels undertaking such treatment, I feel constrained to point out, in the first place, that it certainly cannot be undertaken with any advantage to the patients in a large proportion of the working-class dwellings of our modern towns; and, in the second, that, even under the most favourable conditions, it will be liable to degenerate into a perfunctory and purely nominal supervision in a large proportion of cases, unless the services of the dispensary staff are requisitioned to see that the patients and their friends understand and put into practice the principles of sound curative and preventive treatment.

Now with regard to sanatoria. The Local Government Board, in their memorandum of the I4th May, I9I2, tentatively estimated that about one bed per 5,000 of the population would be required for sanatorium accommodation proper, and another like amount for hospital accommodation-this for the guidance of local authorities in endeavouring to estimate the amount of accommodation to be provided under the new regime. The sanatorium at Nottingham, which has been in existence for several years, will serve as the type of a large class of such institutions attached to municipal hospitals in all parts of this country, and may therefore be described as embodying the approximate requirements of towns like our own at the present stage of the anti-tuberculosis crusade.

It consists of one 30-bed wooden block, two I 2 -bed iron blocks, and some large shelters and adapted farm buildings, containing about 20 beds altogether. These buildings are furnished with verandahs, and generally equipped for convenient use as open-air hospitals or sanatoria for both sexes. Owing to the character and arrangement of the buildings, it is possible to separate cases of different classes, types, and stages from one another, which is frequently of great advantage. The whole sanatorium stands in open country, apart by itself, but within the general isolation hospital enclosure of $12 \frac{1}{2}$ acres, at a distance of about three miles northward from the centre of the city. The hospital enclosure has in its immediate vicinity a large area of agricultural land belonging to the Corporation, suitable for cultivation by convalescent phthisical patients, and upon which also further sanatorium buildings can be erected. Thirty shillings a week is paid by the Insurance Committee for each patient sent in by that body. Until July $\mathrm{I}_{5}$ th, Igr2, when sanatorium benefit under the National Health Insurance Act came into operation, phthisical patients were admitted only on payment of ros. $6 \mathrm{~d}$. a week per head, and, pending the final settlement of the proportional amount of the total cost of providing sanatorium treatment for uninsured persons to be borne by the Treasury, this arrangement continues for the uninsured desiring to enter the institution. Exercise and employment is provided to some extent upon the agricultural land surrounding the hospital and sanatorium, for those in fit condition to work; but the insured patients up to the present have not, as a rule, proved so industrious as those admitted under the old régime. The insured patients appear to regard themselves as State pensioners on holiday, and to consider all work an evil to be avoided as far as possible. $U p$ to the present, moreover, the Insurance Committee's patients have been sent in only for periods too short to be of permanent advantage to them.

In my first report upon the organisation of the Dispensary and Sanatorium Scheme under the Insurance Act, furnished to the City Council and Local Government Board in the early part of $I g I 2$, I recommended the inclusion of the tuberculosis wards of the General Hospital as part of the Sanatorium Unit for the accommodation of cases requiring active surgical treatment, and in the first instance this suggestion met with a favourable reception at the hands of the hospital authorities, especially in view of the fact that such affiliation was to carry with it a payment of 30 s. a week for each patient admitted; but in the end the proposal was rejected on the ground that its acceptance would involve the sacrifice in some measure of the hospital's independence, together with a risk of diminishing its revenue from voluntary contributions. Under existing conditions, therefore, insured and uninsured 
cases of tuberculosis requiring such surgical treatment as cannot conveniently be given at home or at the dispensary or sanatorium must be sent to the General Hospital, as heretofore, with in-patient letters.

No scheme of this character can be considered complete without a hospital for advanced cases, a farm colony, and an open-air school for tuberculous children; but in most towns at the present juncture, with a demand on the one hand from the Local Government Board for the adequate treatment of insured and uninsured alike, coupled with an offer of half the total cost of dealing with the latter from the Imperial Treasury, and on the other hand a strong desire on the part of local authorities to obtain a larger subsidy than this if possible, there is an unmistakable tendency to go slow so far as all new developments are concerned, until these authorities know definitely what they can be compelled to do, and how much of the total cost of what-at the lowest estimate-must be a very large and expensive undertaking they can obtain from an unwilling Exchequer.

\section{ADMINISTRATION OF SANATORIUM} BENEFIT IN COUNTIES.

Dr. Eustace Hill (Durham C.C.) said that Dr. Boobbyer had been dealing with a scheme in being, while a county scheme with which he proposed to deal, was one in posse, and therefore it was difficult to dogmatise too much as to the best methods. It might be taken for granted that the proper body to carry out the administration of sanatorium benefit was the county authority, not the Insurance Committee, or other small bodies. Any scheme for either county or borough should deal with all cases of tuberculosis whether insured or un-insured. In the county area that would be more difficult as the county council was not the executive sanitary authority-that being in the hands of the county boroughs and district councils. There was also an increased difficulty in acquiring hospital accommodation. In addition a much larger number of dispensaries and local hospitals were required than was necessary in a borough. It was not his purpose to go into the principles of the report of the Departmental Committee. The same units were required in a county as for an urban area-dispensaries, hospitals, sanatoria. Before carrying out a scheme an agreement should be made with the Insurance Committee that they would utilise the accommodation provided by the county authority. That was a matter of prime importance. It was also desirable that the County Insurance Committee should make themselves responsible not only for insured persons, but for their dependents. Up to 1915 it would be impossible for the Insurance Committee of large counties to expend the benefit fund for the treatment of insured persons. If they undertook to treat dependents as well as insured persons, it was manifest that the cost to the county would be reduced. It was very desirable that there should be representatives of the County Insurance Committee on the County Health and Tuberculosis Committee; in fact, everything should be done to cause co-operation between the two bodies. A certain number of the Insurance Committee should be asked to attend the meetings of the County Tuberculosis Committee and make themselves acquainted with the progress of the scheme, and report to their own committee. As the result of considerable experience in this matter, he suggested that the County Sanitary and Tuberculosis Committee should be independent of the Health Committee. The question arose as to combination between counties and county boroughs for joint schemes. There were, in his opinion; objections to that. These were: There was undoubtedly delay wherever there were joint committees; in addition, it was strongly held by his own county that there was no control over expenditure. Probably it might be desirable in less populous counties that there should be co-operation in joint dispensaries and sanatoria, and the arrangement should be, payment for services rendered rather than by a joint scheme. In large counties, such as the West Riding, it was most undesirable that the county medical officer should be the tuberculosis officer. It was utterly impossible for a county medical officer to perform his own necessary duties and those of the tuberculosis officer. In small counties a different arrangement might be made for clinical purposes. The adviser of the Insurance Committee should be the tuberculosis officer. The most essential point was that the dispensaries should be sufficiently numerous to avoid unnecessary cost of travelling any distance; but that there should be one dispensary for every I 50 or 200 of the population was quite untenable. In each dispensary there should be four or five rooms - a consulting room, a laboratory, a waiting room, and nursing accommodation. The proposal of the Local Government Board that the cost up to a maximum of $£ 240$ should be agreed to; but his own view was that $£ 240$ would be practically required in every case. In his own county sixteen dispensaries were provided. It was better, in his opinion, instead of building or buying, them, they should be rented, and his estimate was that a sufficient number could be obtained at an average rental of $£ 30$ a year. In that case there would be no capital expenditure charges. The rent would be chargeable to main. tenance, and 50 per cent. of that would be defrayed by the Local Gover nment Board. What 